DOI: 10.1002/zaac.201100216

\title{
The Crystal and Molecular Structure of $\gamma-\mathbf{P}_{4} \mathbf{S}_{6}$
}

\author{
Thomas Rödl ${ }^{[a]}$ and Arno Pfitzner*[a]
}

In Memory of Professor Hans Georg von Schnering

Keywords: Phosphorus; Sulfur; Phosphorus sulfides; Cage molecules

Abstract. The crystal and molecular structure of $\gamma-\mathrm{P}_{4} \mathrm{~S}_{6}$ was determined from single-crystal $\mathrm{X}$-ray diffraction. It crystallizes monoclinically in the space group $P 2 / m$ (No. 11) with $a=6.627(3) \AA, b=$
10.504(7) $\AA, c=6.878(3) \AA, \beta=90.18(4)^{\circ}, V=478.8(4) \AA^{3}$, and $Z=$ 2. The structure consists of cage-like $\mathrm{P}_{4} \mathrm{~S}_{6}$ molecules with $C_{S}$ symmetry arranged with the topology of a cubic close packing.

\section{Introduction}

In general the phosphorus sulfides consist of small cage-like molecules with the composition $\mathrm{P}_{4} \mathrm{~S}_{n}(n=3-10)$. The structures of $a-\mathrm{P}_{4} \mathrm{~S}_{3},{ }^{[1]} \gamma-\mathrm{P}_{4} \mathrm{~S}_{3},{ }^{[1,2]} a-\mathrm{P}_{4} \mathrm{~S}_{4},{ }^{[3]} \alpha-\mathrm{P}_{4} \mathrm{~S}_{5},{ }^{[4]} \beta-\mathrm{P}_{4} \mathrm{~S}_{5},{ }^{[5]} \beta$ $\mathrm{P}_{4} \mathrm{~S}_{6},{ }^{[6]} \quad a-\mathrm{P}_{4} \mathrm{~S}_{7},{ }^{[4,7]} \quad \beta-\mathrm{P}_{4} \mathrm{~S}_{7},{ }^{[8]} \quad \mathrm{P}_{4} \mathrm{~S}_{9}-\mathrm{II},{ }^{[9]} \quad \mathrm{P}_{4} \mathrm{~S}_{9}-\mathrm{III},{ }^{[10]}$ and $\mathrm{P}_{4} \mathrm{~S}_{10}{ }^{[4,7,11]}$ were determined from single-crystal X-ray diffraction. Other phosphorus sulfides like $\mathrm{P}_{4} \mathrm{~S}_{8}$ have been characterized by ${ }^{31} \mathrm{P}$ NMR spectroscopy. ${ }^{[12]}$ They all have in common, that their molecular structures can be derived from the $\mathrm{P}_{4}$ tetrahedron of white phosphorus by either insertion of sulfur atoms into $\mathrm{P}-\mathrm{P}$ bonds or exocyclic addition to phosphorus atoms. Due to the possible combinations a large number of constitution isomers is suggested for each composition. Additionally, different crystal structures of the same molecule are conceivable. In the case of e.g. $\mathrm{P}_{4} \mathrm{~S}_{6}$ five isomers are known, see Figure 1. Among these, only the crystal structure of $\beta-\mathrm{P}_{4} \mathrm{~S}_{6}$ was determined by X-ray diffraction analysis. ${ }^{[6]}$ On the contrary the structures of $a-\mathrm{P}_{4} \mathrm{~S}_{6},{ }^{[13]} \gamma-\mathrm{P}_{4} \mathrm{~S}_{6},{ }^{[14]} \delta-\mathrm{P}_{4} \mathrm{~S}_{6}$, and $\varepsilon-$ $\mathrm{P}_{4} \mathrm{~S}_{6}{ }^{[15]}$ have been characterized only spectroscopically.

$\gamma-\mathrm{P}_{4} \mathrm{~S}_{6}$ has first been observed by Jason as a product in the oxidation of phosphorus by sulfur at low temperatures $\left(<100{ }^{\circ} \mathrm{C}\right)$ and in the sulfurization of $\alpha-\mathrm{P}_{4} \mathrm{~S}_{5}$ by triphenylarsenic sulfide. ${ }^{[14]}$ Based on the signals in the corresponding solution ${ }^{31} \mathrm{P}$ NMR spectra he was able to assign a molecular structure. Herein, we confirm the molecular structure assigned by Jason, and in addition, present the crystal structure of $\gamma-\mathrm{P}_{4} \mathrm{~S}_{6}$.

\section{Results and Discussion}

The crystal and molecular structure of $\gamma-\mathrm{P}_{4} \mathrm{~S}_{6}$ was determined by single-crystal X-ray diffraction. The compound crys-

\footnotetext{
* Prof. Dr. A. Pfitzner

Fax: +49-941-943-814551

E-Mail: arno.pfitzner@chemie.uni-regensburg.de

[a] Institut für Anorganische Chemie

Universität Regensburg

Universitätsstraße 31

93040 Regensburg, Germany
}

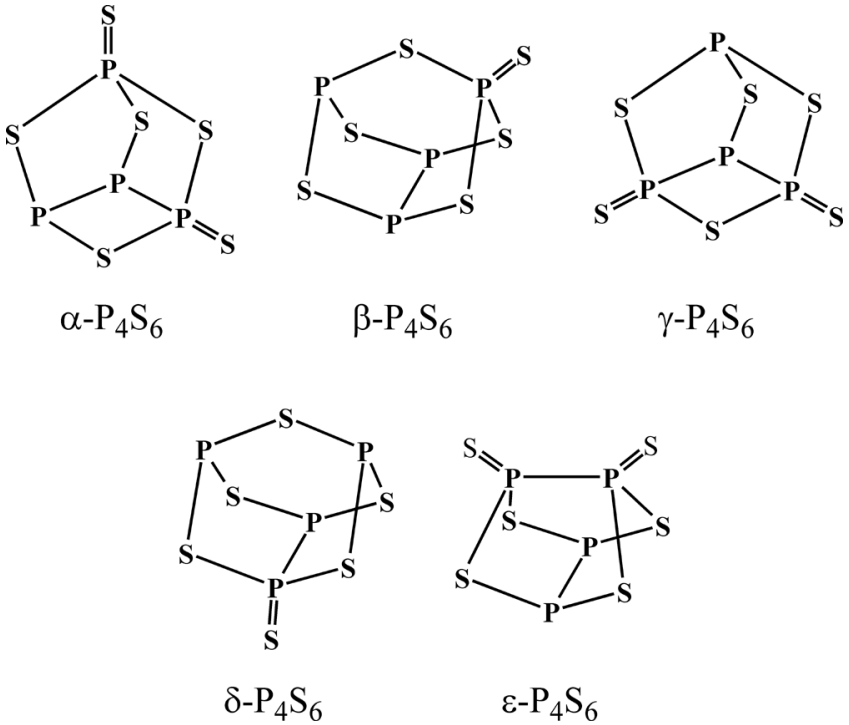

Figure 1. Known molecular structures of $\mathrm{P}_{4} \mathrm{~S}_{6} \cdot{ }^{[6,13-15]}$

tallizes as a pseudomerohedral twin in the monoclinic space group $P 2{ }_{1} / m$ (No. 11) with $a=6.627(3) \AA, b=10.504(7) \AA$, $c=6.878(3) \AA$ and $\beta=90.18(4)^{\circ}$. The monoclinic angle is very close to $90^{\circ}$ and mimics a metrically orthorhombic cell. Analyzing the reflection data with XPREP ${ }^{[16]}$ revealed that the true metric is monoclinic: whereas the internal $R$-value is poor for the higher symmetry $\left(R_{\text {int }}=0.297\right)$ it is very good for the lower symmetry $\left(R_{\mathrm{int}}=0.032\right)$. In the monoclinic setting only the reflection condition for $2_{1} \| b$ was fulfilled indicating the possible space groups $P 2_{1}$ (No. 4 ) and $P 2_{1} / m$ (No. 11). Due to pseudomerohedral twinning the $E$ statistics $\left(\left|E^{2}-1\right|=0.814\right)$ were no real criterion for (non-)centrosymmetry. For this reason the structure solution was performed in the higher- and centrosymmetric space group $P 2_{1} / m$ (No. 11). The structure solution using direct methods was successful and after a few refinement cycles a reasonable structural model was obtained. However, the $R$ values were unusually high at this stage and 
pseudomerohedral twinning had to be taken into account. The possible twin laws were derived from symmetry reduction starting from the apparent Laue class $2 / \mathrm{m} 2 / \mathrm{m} 2 / \mathrm{m}$ and ending up with the true Laue class $2 / m$. Thus, a mirror plane perpendicular to the $a$ axis could be used as a twin element in the refinement procedure. By doing this, the $R$ values dropped significantly from $R_{1}=0.1311$ and $\mathrm{w} R_{2} 0.3174$ to $R_{1}=0.0703$ and $\mathrm{w} R_{2}=0.1758$ (for all data). Table 1 shows the results of the refinement for $\gamma-\mathrm{P}_{4} \mathrm{~S}_{6}$. The atomic coordinates and anisotropic displacement parameters are listed in Table 2 and Table 3.

Table 1. Crystallographic data for $\gamma-\mathrm{P}_{4} \mathrm{~S}_{6} \cdot{ }^{a)}$

\begin{tabular}{|c|c|}
\hline Compound & $\gamma-\mathrm{P}_{4} \mathrm{~S}_{6}$ \\
\hline Formula Weight $/ \mathrm{g} \cdot \mathrm{mol}^{-1}$ & 316.24 \\
\hline Colour & yellow \\
\hline Crystal system, space group & monoclinic, $P 2_{1} / m$ (No.11) \\
\hline \multicolumn{2}{|l|}{ Lattice constants } \\
\hline$a / \AA$ & $6.627(3)$ \\
\hline$b / \AA$ & $10.504(7)$ \\
\hline$c / \AA$ & $6.878(3)$ \\
\hline$\beta /^{\circ}$ & $90.18(4)$ \\
\hline Volume $V / \AA^{3}$ & $478.8(4)$ \\
\hline Number of formula units $Z$ & 2 \\
\hline Calculated density $\rho_{\text {calc }} / \mathrm{g} \cdot \mathrm{cm}^{-3}$ & 2.194 \\
\hline Temperature $T / \mathrm{K}$ & $293(2)$ \\
\hline Diffractometer & Stoe IPDS I \\
\hline Wavelength $\lambda / \AA$ & $0.71073\left(\mathrm{Mo}-K_{\alpha}\right)$ \\
\hline Absorption coeff. $\mu\left(\right.$ Mo- $\left.K_{\alpha}\right) / \mathrm{mm}^{-1}$ & 2.018 \\
\hline$\theta$ range of data collection $/^{\circ}$ & $2.96-25.19$ \\
\hline \multirow[t]{3}{*}{ Index ranges } & $-7 \leq h \leq 7$ \\
\hline & $-12 \leq k \leq 12$ \\
\hline & $-8 \leq l \leq 8$ \\
\hline \multirow[t]{2}{*}{ Absorption correction } & numerical, X-RED ${ }^{[17]}$ \\
\hline & and X-SHAPE ${ }^{[18]}$ \\
\hline No. of reflections collected & 6288 \\
\hline (independent) & $(905)$ \\
\hline$R_{\sigma}, R_{\mathrm{int}}$ & $0.0353,0,0525$ \\
\hline Completeness to $\theta=25.19^{\circ}$ & $99.6 \%$ \\
\hline Structure solution & SIR92 $2^{[19]}$ \\
\hline Structure refinement & SHELXL-97 ${ }^{[20]}$ \\
\hline No. of refined parameters & 53 \\
\hline No. of restraints & 0 \\
\hline GooF & 1.142 \\
\hline Twin law & $-100,010,0001$ \\
\hline Batch scale factor BASF & $0.138(4)$ \\
\hline$R_{1}, \mathrm{w} R_{2}[I>2 \sigma(I)]$ & $0.0604,0.1705$ \\
\hline$R_{1}, \mathrm{w} R_{2}$ [all data] & $0.0703,0.1758$ \\
\hline Largest diff. peak \& hole $/ \mathrm{e} \cdot \AA^{-3}$ & 1.635 and -0.418 \\
\hline
\end{tabular}

a) Further details on the crystal structure investigations may be obtained from the Fachinformationszentrum Karlsruhe, 76344 Eggenstein-Leopoldshafen, Germany (Fax: +49-7247-808-666; E-Mail: crysdata@fiz-karlsruhe.de), on quoting the depository number CSD423037.

As it is common for phosphorus sulfides the structure of $\gamma$ $\mathrm{P}_{4} \mathrm{~S}_{6}$ consists of discrete cage-like molecules. The molecular structure can be derived from the $\mathrm{P}_{4}$ tetrahedron of white phosphorus by introducing four bridging and two terminal sulfur atoms, see Figure 2. A single $\gamma-\mathrm{P}_{4} \mathrm{~S}_{6}$ molecule exhibits only one symmetry element, a mirror plane through the atoms $\mathrm{P}(2)$, $\mathrm{P}(3), \mathrm{S}(3)$ and $\mathrm{S}(4)$. Thus, the molecules are achiral and belong to the point group $C_{s}$. The intramolecular distances and angles in $\gamma-\mathrm{P}_{4} \mathrm{~S}_{6}$ are summarized in Table 4 . They are in good agree-
Table 2. Atomic coordinates and equivalent isotropic displacement parameters $U_{e q}{ }^{\text {a) }}$ (in $\AA^{2}$ ) for $\gamma-\mathrm{P}_{4} \mathrm{~S}_{6}$.

\begin{tabular}{llllll}
\hline Atom & Wyck. & $x$ & $y$ & $z$ & $U_{\text {eq }}$ \\
\hline $\mathrm{P}(1)$ & $4 f$ & $0.2485(3)$ & $0.1118(2)$ & $0.2612(4)$ & $0.040(1)$ \\
$\mathrm{P}(2)$ & $2 e$ & $0.2046(5)$ & 0.25 & $0.5084(5)$ & $0.044(1)$ \\
$\mathrm{P}(3)$ & $2 e$ & $0.6795(5)$ & 0.25 & $0.3851(6)$ & $0.053(1)$ \\
$\mathrm{S}(1)$ & $4 f$ & $0.1055(3)$ & $0.5460(2)$ & $0.2492(4)$ & $0.051(1)$ \\
$\mathrm{S}(2)$ & $4 f$ & $0.5638(3)$ & $0.0890(2)$ & $0.2396(4)$ & $0.053(1)$ \\
$\mathrm{S}(3)$ & $2 e$ & $0.1533(6)$ & 0.25 & $0.0562(6)$ & $0.054(1)$ \\
$\mathrm{S}(4)$ & $2 e$ & $0.4878(5)$ & 0.25 & $0.6368(6)$ & $0.053(1)$ \\
\hline
\end{tabular}

a) $U_{e q}$ is defined as one third of the trace of the orthogonalized $U_{i j}$ tensor.

Table 3. Anisotropic displacement parameters $U^{i j}\left(\right.$ in $\AA^{2} \times 10^{3}$ ) for $\gamma-\mathrm{P}_{4} \mathrm{~S}_{6}$

\begin{tabular}{lllllll}
\hline Atom & $U_{11}$ & $U_{22}$ & $U_{33}$ & $U_{23}$ & $U_{13}$ & $U_{12}$ \\
\hline $\mathrm{P}(1)$ & $35(1)$ & $39(1)$ & $46(1)$ & $-2(1)$ & $-1(1)$ & $-2(1)$ \\
$\mathrm{P}(2)$ & $39(2)$ & $41(2)$ & $52(2)$ & 0 & $5(1)$ & 0 \\
$\mathrm{P}(3)$ & $30(2)$ & $55(2)$ & $74(3)$ & 0 & $0(2)$ & 0 \\
$\mathrm{~S}(1)$ & $47(1)$ & $43(1)$ & $63(2)$ & $0(1)$ & $-8(1)$ & $7(1)$ \\
$\mathrm{S}(2)$ & $35(1)$ & $48(1)$ & $75(2)$ & $-8(1)$ & $3(1)$ & $5(1)$ \\
$\mathrm{S}(3)$ & $59(2)$ & $45(2)$ & $59(2)$ & 0 & $-23(2)$ & 0 \\
$\mathrm{~S}(4)$ & $45(2)$ & $58(2)$ & $58(2)$ & 0 & $-12(2)$ & 0 \\
\hline
\end{tabular}

ment with those in other phosphorus sulfides. The distance $\mathrm{P}(1)-\mathrm{P}(2)$ is $2.255(4) \AA$. The exocyclic phosphorus sulfur distance $d(\mathrm{P}(1)-\mathrm{S}(1))=1.912(3) \AA$ is as expected shorter than the distances between phosphorus and bridging sulfur atoms which vary in the range from $2.071(5) \AA$ to $2.151(6) \AA$.

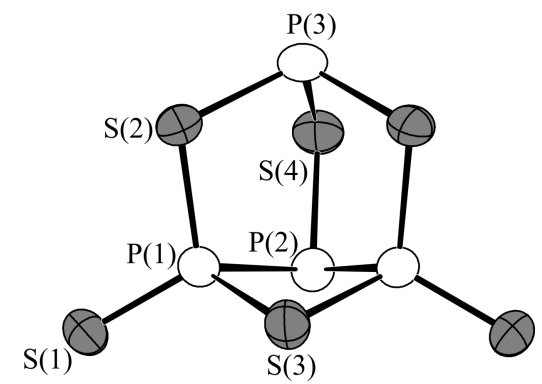

Figure 2. Single $\gamma-\mathrm{P}_{4} \mathrm{~S}_{6}$ molecule. Ellipsoids are drawn at $75 \%$ probability level.

Table 4. Selected interatomic distances (in $\AA$ ) and angles (in ${ }^{\circ}$ ) in $\gamma-\mathrm{P}_{4} \mathrm{~S}_{6}$.

\begin{tabular}{llll}
\hline $\mathrm{P}(1)-\mathrm{S}(1)$ & $1.912(3)$ & $\mathrm{S}(1)^{\# 1}-\mathrm{P}(1)-\mathrm{S}(2)$ & $112.9(1)$ \\
$\mathrm{P}(1)-\mathrm{S}(2)$ & $2.109(3)$ & $\mathrm{S}(1)^{\# 1}-\mathrm{P}(1)-\mathrm{S}(3)$ & $114.8(2)$ \\
$\mathrm{P}(1)-\mathrm{S}(3)$ & $2.118(4)$ & $\mathrm{S}(2)-\mathrm{P}(1)-\mathrm{S}(3)$ & $108.9(2)$ \\
$\mathrm{P}(1)-\mathrm{P}(2)$ & $2.255(4)$ & $\mathrm{S}(1)^{\# 1}-\mathrm{P}(1)-\mathrm{P}(2)$ & $121.7(2)$ \\
$\mathrm{P}(2)-\mathrm{S}(4)$ & $2.071(5)$ & $\mathrm{S}(2)-\mathrm{P}(1)-\mathrm{P}(2)$ & $104.8(2)$ \\
$\mathrm{P}(3)-\mathrm{S}(2)$ & $2.108(4)$ & $\mathrm{S}(3)-\mathrm{P}(1)-\mathrm{P}(2)$ & $91.3(1)$ \\
$\mathrm{P}(3)-\mathrm{S}(4)$ & $2.151(6)$ & $\mathrm{S}(4)-\mathrm{P}(2)-\mathrm{P}(1)$ & $101.7(2)$ \\
& & $\mathrm{P}(1)-\mathrm{P}(2)-\mathrm{P}(1)^{\# 1}$ & $80.1(2)$ \\
& & $\mathrm{S}(2)-\mathrm{P}(3)-\mathrm{S}(2)^{\# 1}$ & $106.7(2)$ \\
& & $\mathrm{S}(2)-\mathrm{P}(3)-\mathrm{S}(4)$ & $99.6(2)$ \\
& & $\mathrm{P}(3)-\mathrm{S}(2)-\mathrm{P}(1)$ & $103.6(1)$ \\
& & $\mathrm{P}(1)^{\# 1}-\mathrm{S}(3)-\mathrm{P}(1)$ & $86.5(2)$ \\
& & $\mathrm{P}(2)-\mathrm{S}(4)-\mathrm{P}(3)$ & $101.1(2)$ \\
\hline
\end{tabular}

\#1 symmetry transformation used to generate equivalent atoms: $x$, $-y+1 / 2, z$ 
Each unit cell contains two equivalent $\gamma-\mathrm{P}_{4} \mathrm{~S}_{6}$ molecules related by a $2_{1}$ screw axis along $b$. The shortest intermolecular distances are $3.58(3) \AA$ for $\mathrm{P}(2) \cdots \mathrm{P}(3), \quad 3.41(4) \AA$ for $\mathrm{P}(2) \cdots \mathrm{S}(1)$ and 3.45(4) $\AA$ for $\mathrm{S}(1) \cdots \mathrm{S}(3)$. Hence, weak van der Waals forces are present between adjacent molecules. Figure 3 shows a section of the crystal structure of $\gamma-\mathrm{P}_{4} \mathrm{~S}_{6}$ illustrating the molecular arrangement. Considering the cages to be almost spherical it is strongly related to a cubic closest packing of spheres. The symmetry relations are explained with the help of a Bärnighausen tree, see Figure 4. The low symmetry of the molecules enforces a reduction of the space group symmetry. Due to the non-ideal spherical shape of the molecules there are deviations from a perfect fcc packing resulting in a slight shift of the molecular centre from the ideal position and a significant distortion of the lattice. This finding is not surprising since $\alpha-\mathrm{P}_{4} \mathrm{~S}_{3}, \gamma-\mathrm{P}_{4} \mathrm{~S}_{3}, \alpha-\mathrm{P}_{4} \mathrm{Se}_{3}$ and $\alpha-\mathrm{As}_{4} \mathrm{~S}_{3}$ show quite similar deviations, albeit this time from a hexagonal packing of spheres.

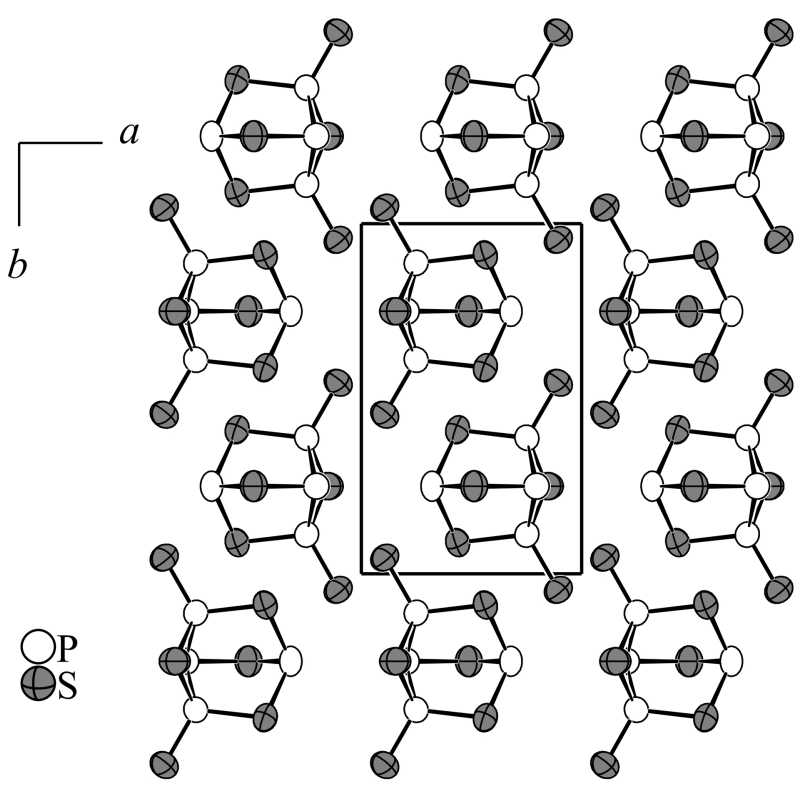

Figure 3. Section of the crystal structure of $\gamma-\mathrm{P}_{4} \mathrm{~S}_{6}$ with view along $c$.

Note added in proof: In the meantime, the crystal structures of polymeric phosphorus polysulfides $\alpha-\mathrm{P}_{2} \mathrm{~S}_{7}$ and $\beta-\mathrm{P}_{2} \mathrm{~S}_{7}$ were determined. They show a ratio of P:S $<4: 10$ and are the first well-characterized crystalline polymeric phosphorus polysulfides. ${ }^{[21]}$

\section{Experimental Section}

$\mathrm{P}_{4} \mathrm{~S}_{3}$ was prepared by reaction of stoichiometric amounts of the elements, phosphorus (Hoechst, 99.999\%) and sulfur (Chempur, $99.999 \%$ ) in an evacuated silica ampoule at $300{ }^{\circ} \mathrm{C}$ and purified by recrystallization from toluene (Merck, p.A.). Commercial $\mathrm{FeCl}_{3}$ (Fluka, $>98 \%$ ) was purified by sublimation in a stream of chlorine gas at $250{ }^{\circ} \mathrm{C}$.

Synthesis of $\gamma-\mathbf{P}_{4} \mathbf{S}_{6}$. Equimolar amounts of $\mathrm{P}_{4} \mathrm{~S}_{3}$ and anhydrous $\mathrm{FeCl}_{3}$ were dissolved in a 2:1 solvent mixture of dry carbon disulfide and chloroform. The reaction mixture was kept in a Schlenk flask under

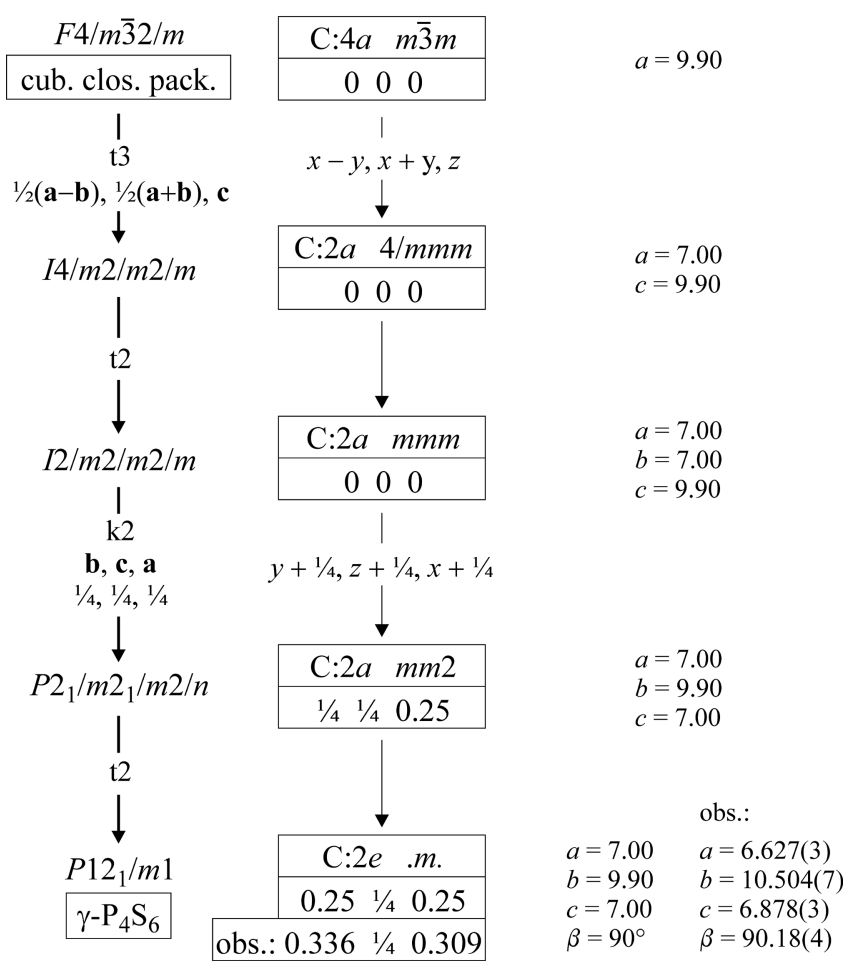

Figure 4. Bärnighausen tree relating a cubic closest packing of spheres with the molecular arrangement in $\gamma-\mathrm{P}_{4} \mathrm{~S}_{6}$. Only the centre of the molecule $(\mathrm{C})$ is displayed.

argon atmosphere for eight weeks. The solvent was then removed by slow evaporation under inert gas conditions at room temperature, yielding some crystals of $\gamma-\mathrm{P}_{4} \mathrm{~S}_{6}$, together with larger amounts of unreacted starting materials. The air- and moisture-sensitive yellow crystals of $\gamma-\mathrm{P}_{4} \mathrm{~S}_{6}$ were manipulated under argon atmosphere in a glovebox and a crystal suitable for the X-ray diffraction analysis was sealed in a glass capillary. The measurement was carried out on a STOE IPDS I diffractometer with $\lambda=0.71073 \AA\left(\mathrm{Mo}-K_{a}\right)$. Further details on the data collection are shown in Table 1.

\section{References}

[1] a) Y. C. Leung, J. Waser, S. van Houten, A. Vos, G. A. Wiegers, E. H. Wiebenga, Acta Crystallogr. 1957, 10, 574-582; b) T. K. Chattopadhyay, W. May, H. G. von Schnering, G. S. Pawley, Z. Kristallogr. 1983, 165, 47-64; c) I. Raabe, S. Antonijevic, I. Krossing, Chem. Eur. J. 2007, 13, 7510-7522.

[2] H. Gruber, U. Müller, Z. Kristallogr. 1997, 212, 662-664.

[3] a) A. M. Griffin, P. C. Minshall, G. M. Sheldrick, J. Chem. Soc., Chem. Commun. 1976, 809-810; b) P. C. Minshall, G. M. Sheldrick, Acta Crystallogr., Sect. B 1978, 34, 1326-1328; c) C.-C. Chang, R. C. Haltiwanger, A. D. Norman, Inorg. Chem. 1978, 17, 2056-2062.

[4] a) S. van Houten, E. H. Wiebenga, Acta Crystallogr. 1957, 10, 156-160; b) A. Vos, R. Olthof, F. van Bolhuis, R. Botterweg, Acta Crystallogr. 1965, 19, 864-867.

[5] A. M. Griffin, G. M. Sheldrick, Acta Crystallogr., Sect. B 1975, 31, 2738-2740.

[6] R. Blachnik, U. Peukert, A. Czediwoda, B. Engelen, K. Boldt, Z. Anorg. Allg. Chem. 1995, 621, 1637-1643.

[7] A. Vos, E. H. Wiebenga, Acta Crystallogr. 1955, 8, 217-223. 
[8] D. T. Dixon, F. W. Einstein, B. R. Penfold, Acta Crystallogr. 1965, 18, 221-225.

[9] W. Wilmer, Acta Crystallogr., Sect. B 1969, 25, 1229-1232.

[10] B. Wallis, G. U. Wolf, P. Leibnitz, Z. Anorg. Allg. Chem. 1990, 588, 139-146.

[11] R. Blachnik, J. Matthiesen, A. Müller, H. Nowottnick, H. Reuter, Z. Kristallogr. - New Cryst. Struct. 1998, 213, 233-234.

[12] J.-J. Barieux, M. C. Demarcq, J. Chem. Soc., Chem. Commun. 1982, 176-177.

[13] T. Bjorholm, H. J. Jakobsen, J. Am. Chem. Soc. 1991, 113, 2732.

[14] a) M. E. Jason, T. Ngo, S. Rahman, Inorg. Chem. 1997, 36, 2633 2640; b) M. E. Jason, Inorg. Chem. 1997, 36, 2641-2646.
[15] H. Nowottnick, R. Blachnik, Z. Anorg. Allg. Chem. 1999, 625, 1966-1968.

[16] XPREP, Reciprocal Space Exploration, Ver. 2005/2, Bruker AXS, 2005.

[17] $X$-RED32, STOE \& Cie GmbH, 2004.

[18] X-SHAPE, STOE \& Cie GmbH, 1999.

[19] A. Altomare, M. C. Burla, M. Camalli, G. Cascarano, C. Giacovazzo, A. Guagliardi, G. Polidori, J. Appl. Crystallogr. 1994, 27, 435.

[20] G. M. Sheldrick, Acta Crystallogr., Sect. A 2008, 64, 112.

[21] T. Rödl, R. Weihrich, J. Wack, J. Senker, A. Pfitzner, Angew. Chem. Int. Ed. 2011, in press. DOI: 10.1002/anie.201103485.

Received: May 9, 2011 Published Online: August 20, 2011 